Polymer Journal, Vol. 39, No. 6, pp. 524-530 (2007)

(C) 2007 The Society of Polymer Science, Japan

\title{
Catalytic Oxidative Cross-Coupling Polymerization of Unsymmetric Binaphthol Derivatives Using Cu(I)-Bisoxazoline Complexes
}

\author{
Tomohisa Temma, Yusuke Takahashi, Yasuhiro Yoshit, and Shigeki HabauE ${ }^{\dagger}$ \\ Department of Chemistry and Chemical Engineering, Yamagata University, Yonezawa 992-8510, Japan
}

(Received December 5, 2006; Accepted March 2, 2007; Published April 17, 2007)

\begin{abstract}
The asymmetric oxidative coupling polymerization of 6,6'-dihydroxy-2,2'-binaphthalene derivatives or methyl 3,7-dihydroxy-2-naphthoate, having an unsymmetric 2-naphthol structure, with copper catalysts under an $\mathrm{O}_{2}$ atmosphere was carried out. The polymerization using the $\mathrm{CuCl}-(S)-2,2^{\prime}$-isopropylidenebis(4-phenyl-2-oxazoline) catalyst afforded a polymer with a high cross-coupling selectivity of up to $99 \%$, which showed a number average molecular weight of 5.0-9.1 $\times 10^{3}$. To estimate the stereoselectivity during the polymerization, a model reaction was examined which resulted in good to high cross-coupling selectivities, while the enantioselectivities were low. The polymer composed of a homo-coupling unit showed a photoluminescence spectral pattern similar to that of the model compound. In contrast, a very different emission, which may be due to the excimer, from that of the model was observed for the polymer consisted of the cross-coupling unit. [doi:10.1295/polymj.PJ2006183]
\end{abstract}

KEY WORDS Asymmetric Oxidative Coupling / Cross-Coupling / Binaphthol /

Optically active and racemic 1,1'-binaphthyl-based polymers have been extensively studied, for example, as electroluminescent materials due to the fact that the conjugation length of a polymer could be controlled without inserting a nonconjugated spacer group into the polymer main chain. ${ }^{1}$ Lin et al. investigated the synthesis and optical spectroscopic studies of a series of binaphthyl-based oligomers, from quaternaphthyls to decanaphthyls, and enantioselective fluorescence quenching of hexanaphthols by treatment with trans1,2-diaminocyclohexane. ${ }^{1 \mathrm{~b}} \mathrm{Pu}$ et al. reported that the 1,1'-binaphthyl-based polymer exhibits an electroluminescence property in a double-layered light emitting diode. ${ }^{1 \mathrm{c}}$

On the other hand, the oxidative coupling reaction of the 2-naphthol derivatives is a facile synthetic route for the 1,1'-bi-2-naphthol skeleton, and many chiral metal catalysts, such as $\mathrm{Cu}(\mathrm{I}), \mathrm{Ru}(\mathrm{II})$, and V(IV), have been developed to control its axially dissymetric stereochemistry. ${ }^{2}$ Recently, we found that the asymmetric oxidative coupling reaction between two differently substituted 2-naphthol derivatives using the $\mathrm{CuCl}-(S)$ 2,2'-isopropylidenebis(4-phenyl-2-oxazoline) $[\mathrm{CuCl}-$ $(S)$ Phbox] catalyst, affords a product with a high cross-coupling selectivity, ${ }^{3}$ although few data have been available for the catalytic oxidative cross-coupling reaction leading to an unsymmetrical binaphthol structure. The cross-coupling- and stereo-selectivities were significantly affected by the substituents on 2naphthol and the ester groups of 3-hydroxy-2-naphthoate. ${ }^{3}$ This method was further used for the polymerization of the methyl 6,6'-dihydroxy-2,2'-binaphthalene-7-carboxylate as a monomer affording a polymer with the high cross-coupling selectivity of $96 \%$. $^{4}$

Herein, the oxidative coupling polymerization of the new monomers, various unsymmetrically substituted 6,6'-binaphthol derivatives $\mathbf{1}$ and methyl 3,7-dihydroxynaphthalene-2-carboxylate 2 , with the copper-diamine catalysts, such as di- $\mu$-hydroxo$\operatorname{bis}\left[\left(N, N, N^{\prime}, N^{\prime}\right.\right.$-tetramethylethylenediamine $)$ copper(II)] chloride [CuCl $(\mathrm{OH})$-TMEDA $], \mathrm{CuCl}-(S)$-Phbox, $\mathrm{CuCl}-(R)-(-)-2,2^{\prime}$-isopropulidenebis(4-benzyl-2-oxazoline) $[(R)$-Bnbox $] \mathrm{CuCl}-(+)-1$-(2-pyrrolidinylmethyl)pyrrolidine $[(+) \mathrm{PMP}]$, and $\mathrm{CuCl}_{2}-(-)$-sparteine $[(-) \mathrm{Sp}]$ (Figure 1), is carried out, and the effect on the coupling selectivities of the substituents during the oxidative coupling polymerization and character-

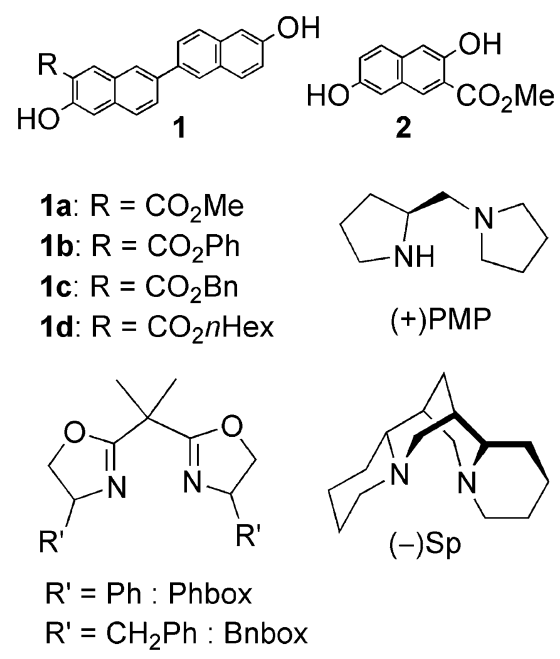

Figure 1. Monomers and chiral ligands.

${ }^{\dagger}$ To whom correspondence should be addressed (Tel/Fax: +81-238-26-3116, E-mail: habaue@yz.yamagata-u.ac.jp). 


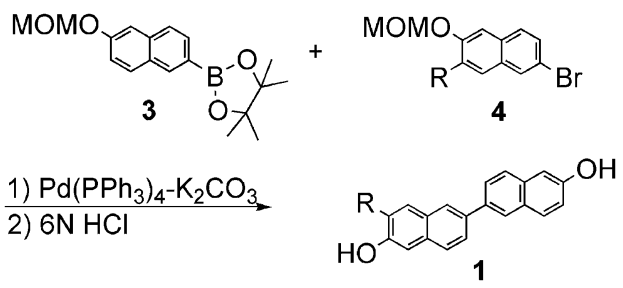

Scheme 1.

istics of the polybinaphthyls as an emissive material are investigated.

\section{EXPERIMENTAL}

\section{Materials}

Dry THF (Kanto) was used for the oxidative coupling reactions. The optically active diamines, (+)PMP (TCI) and (-)Sp (Sigma), were dried over $\mathrm{CaH}_{2}$ and then distilled under reduced pressure. The bisoxazolines, (S)Phbox and (R)Bnbox (Aldrich), were used as received. The achiral copper complex, $\mathrm{CuCl}(\mathrm{OH})-\mathrm{TMEDA}$, was purchased from TCI.

\section{Synthesis of Monomers $\mathbf{1}^{4}$ (Scheme 1).}

Compound 3 was synthesized from 6-bromo-2naphthol by methoxymethylation with $\mathrm{NaH}$ and chloromethyl methyl ether, followed by the reaction with 2-isopropoxy-4,4,5,5,-tetramethyl-1,3,2-dioxaborolane after lithiation with $n$-BuLi. Compound 4 was prepared from 7-bromo-3-hydroxy-2-naphthoic acid by esterification and methoxymethylation.

Monomer 1 was synthesized by the Suzuki coupling reaction between 3 and $\mathbf{4}$ in the presence of $\mathrm{Pd}\left(\mathrm{PPh}_{3}\right)_{4}$ and $1 \mathrm{M} \mathrm{K}_{2} \mathrm{CO}_{3}$, followed by treatment with $6 \mathrm{~N} \mathrm{HCl}$ to remove the methoxymethyl ether, and purified by silica gel column chromatography.

lb: ${ }^{1} \mathrm{H}$ NMR $\left(200 \mathrm{MHz}, \mathrm{CDCl}_{3}\right) 10.20(\mathrm{~s}, 1 \mathrm{H},-\mathrm{OH})$, 8.17-7.81 (m, 7H, aromatic), 7.54-7.13 (m, 9H, aromatic), $5.03(\mathrm{~s}, 1 \mathrm{H},-\mathrm{OH})$. IR $\left(\mathrm{KBr}, \mathrm{cm}^{-1}\right) 3474$, 3261, 1695, 1509, 1338, 1299, 1286, 1209, 1193, 1155. MS (FAB) $m / z 406[\mathrm{M}]^{+}$. Anal. calcd for $\mathrm{C}_{27} \mathrm{H}_{18} \mathrm{O}_{4}$ : C, 79.79; H, 4.46. Found: C, 79.61; H, 4.60 .

1c: ${ }^{1} \mathrm{H}$ NMR (200 MHz, DMSO- $\left.d_{6}\right) 10.32(\mathrm{~s}, 1 \mathrm{H}$, $-\mathrm{OH}), 9.81(\mathrm{~s}, 1 \mathrm{H},-\mathrm{OH}), 8.59-8.21$ (s, $2 \mathrm{H}$, aromatic), 8.04-7.75 (m, 6H, aromatic), 7.58-7.38 (m, 6H, aromatic), 7.14-7.09 (s, 2H, aromatic), $5.45(\mathrm{~s}, 2 \mathrm{H}$, $\left.-\mathrm{CH}_{2}-\right)$. IR $\left(\mathrm{KBr}, \mathrm{cm}^{-1}\right) 3355,2360,1683,1513$, $1463,1409,1336,1307,1284,1211,1155$. MS (FAB) $m / z 420[\mathrm{M}]^{+}$. Anal. calcd for $\mathrm{C}_{28} \mathrm{H}_{20} \mathrm{O}_{4}: \mathrm{C}, 79.98 ; \mathrm{H}$, 4.79. Found: C, 79.71; H, 5.15.

Id: ${ }^{1} \mathrm{H}$ NMR (200 MHz, $\left.\mathrm{CDCl}_{3}\right) 10.59(\mathrm{~s}, 1 \mathrm{H},-\mathrm{OH})$, $8.57(\mathrm{~s}, 1 \mathrm{H}$, aromatic), 8.11-7.77 (m, 7H, aromatic), 7.35-7.12 (m, 3H, aromatic), $5.02(\mathrm{~s}, 1 \mathrm{H},-\mathrm{OH}), 4.44$ $\left(\mathrm{t}, 2 \mathrm{H}, J=6.8 \mathrm{~Hz},-\mathrm{OCH}_{2}-\right), 1.91-1.83(\mathrm{~m}, 2 \mathrm{H}$,
$\left.-\mathrm{CH}_{2}-\right), 1.43-1.36\left(\mathrm{~m}, 6 \mathrm{H},-\mathrm{CH}_{2}-\right), 0.97-0.89$ (m, $\left.3 \mathrm{H},-\mathrm{CH}_{3}\right)$. IR $\left(\mathrm{KBr}, \mathrm{cm}^{-1}\right) 3436,3216,2956,2931$, $1681,1509,1463,1307,1286,1213$. MS (FAB) $\mathrm{m} / z$ $414[\mathrm{M}]^{+}$. Anal. calcd for $\mathrm{C}_{27} \mathrm{H}_{26} \mathrm{O}_{4}: \mathrm{C}, 78.24 ; \mathrm{H}$, 6.32. Found: C, 78.24; H, 6.19.

\section{Typical Polymerization Procedure}

A monomer was added to a mixture of $\mathrm{CuCl}$ and a diamine in $\mathrm{THF}([\mathbf{1}]=0.13 \mathrm{M},[\mathrm{Cu}(\mathrm{I})] /[$ diamine $] /$ $[1]=0.2 / 0.25 / 1)$. The mixture was stirred at room temperature under an $\mathrm{O}_{2}$ atmosphere. After stirring for $24 \mathrm{~h}$, the polymer was isolated as the methanolethyl acetate- $1 \mathrm{~N} \mathrm{HCl}(2 / 1 / 0.3 \mathrm{v} / \mathrm{v} / \mathrm{v})$-insoluble fraction by centrifugation and drying in vacuo.

\section{Cross-Coupling Reaction}

The mono-methoxymethylated compounds, $\mathbf{5}$ and $\mathbf{6}$, were prepared from $\mathbf{1}$ by methoxymethylation with $\mathrm{NaH}$ and chloromethyl methyl ether. ${ }^{4}$

A mixture of $\mathrm{CuCl}$, diamine, and $\mathrm{THF}$ was stirred for $30 \mathrm{~min}$ under an $\mathrm{O}_{2}$ atmosphere. To this mixture, 5 and $\mathbf{6}$ were added $([\mathrm{CuCl}] /[$ diamine $] /[\mathbf{5}] /[\mathbf{6}]=$ $0.2 / 0.25 / 0.5 / 0.5,[5]=0.065 \mathrm{M})$. The reaction mixture was stirred at room temperature for $3 \mathrm{~h}$, diluted with $\mathrm{CHCl}_{3}$, and washed with $1 \mathrm{~N} \mathrm{HCl}$. The organic layer was then dried over $\mathrm{MgSO}_{4}$. Filtration and concentration then afforded the crude products. The cross-coupling compound was isolated by silica gel column chromatography.

$8 \boldsymbol{b}:{ }^{1} \mathrm{H}$ NMR $\left(200 \mathrm{MHz}, \mathrm{CDCl}_{3}\right) 10.62(\mathrm{~s}, 1 \mathrm{H},-\mathrm{OH})$, 9.09 (s, $1 \mathrm{H}$, aromatic), 8.60 (s, $1 \mathrm{H}$, aromatic), 8.827.24 (s, 28H, aromatic), 5.39 (s, $\left.2 \mathrm{H},-\mathrm{OCH}_{2} \mathrm{O}-\right), 5.30$ (s, $\left.3 \mathrm{H},-\mathrm{OCH}_{2} \mathrm{O}-,-\mathrm{OH}\right), 3.59-3.53\left(\mathrm{~m}, 6 \mathrm{H},-\mathrm{OCH}_{3}\right)$. IR $\left(\mathrm{KBr}, \mathrm{cm}^{-1}\right) 3419,1747,1693,1631,1600,1494$, 1243, 1193, 1162, 1151. MS (FAB) $m / z 898\left[\mathrm{M}^{+}\right.$. Anal. calcd for $\mathrm{C}_{58} \mathrm{H}_{42} \mathrm{O}_{10}$ : C, 77.49; H, 4.71. Found: C, $77.50 ; \mathrm{H}, 4.74$.

8c: ${ }^{1} \mathrm{H}$ NMR $\left(200 \mathrm{MHz}, \mathrm{CDCl}_{3}\right) 10.93(\mathrm{~s}, 1 \mathrm{H},-\mathrm{OH})$, 8.83 (s, 1H, aromatic), 8.40-8.20 (s, 29H, aromatic), $5.52\left(\mathrm{~s}, 2 \mathrm{H},-\mathrm{OCH}_{2}-\right), 5.42\left(\mathrm{~s}, 2 \mathrm{H},-\mathrm{OCH}_{2}-\right), 5.36$ (s, $\left.2 \mathrm{H},-\mathrm{OCH}_{2} \mathrm{O}-\right), 5.06\left(\mathrm{~s}, 2 \mathrm{H},-\mathrm{OCH}_{2} \mathrm{O}-\right), 3.54$ (s, $\left.3 \mathrm{H},-\mathrm{OCH}_{3}\right), 3.53\left(\mathrm{~s}, 3 \mathrm{H},-\mathrm{OCH}_{3}\right) . \mathrm{IR}\left(\mathrm{KBr}, \mathrm{cm}^{-1}\right)$ 3372 , 2953, 1716, 1677, 1629, 1600, 1498, 1272, 1195, 1151. MS (FAB) $\mathrm{m} / z 926[\mathrm{M}]^{+}$. Anal. calcd for $\mathrm{C}_{60} \mathrm{H}_{46} \mathrm{O}_{10}$ : C, 77.74; H, 5.00. Found: C, 77.75; $\mathrm{H}, 4.97$.

8d: ${ }^{1} \mathrm{H}$ NMR (200 MHz, $\left.\mathrm{CDCl}_{3}\right) 11.05(\mathrm{~s}, 1 \mathrm{H},-\mathrm{OH})$, 8.84 (s, 1H, aromatic), 8.33-8.26 (s, 19H, aromatic), $5.37\left(\mathrm{~s}, 2 \mathrm{H},-\mathrm{OCH}_{2} \mathrm{O}-\right), 5.32\left(\mathrm{~s}, 2 \mathrm{H},-\mathrm{OCH}_{2} \mathrm{O}-\right)$, $5.08(\mathrm{~s}, 1 \mathrm{H},-\mathrm{OH}), 4.50\left(\mathrm{t}, 2 \mathrm{H}, J=6.6 \mathrm{~Hz},-\mathrm{OCH}_{2}-\right.$ ), $4.37\left(\mathrm{t}, 2 \mathrm{H}, J=6.6 \mathrm{~Hz},-\mathrm{OCH}_{2}-\right), 3.57(\mathrm{~s}, 3 \mathrm{H}$, $\left.-\mathrm{OCH}_{3}\right), 3.54\left(\mathrm{~s}, 3 \mathrm{H},-\mathrm{OCH}_{3}\right), 1.96-1.75(\mathrm{~m}, 4 \mathrm{H}$, $\left.-\mathrm{CH}_{2}-\right), 1.44-1.36\left(\mathrm{~m}, 12 \mathrm{H},-\mathrm{CH}_{2}-\right), 0.96-0.90(\mathrm{~m}$, $\left.6 \mathrm{H},-\mathrm{CH}_{3}\right)$. IR $\left(\mathrm{KBr}, \mathrm{cm}^{-1}\right) 2945,2929,1724,1716$, $1677,1600,1504,1344,1195,1151$. MS (FAB) $\mathrm{m} / z$ 
T. TEMMA et al.

Table I. Asymmetric OCP of $\mathbf{1}^{\text {a }}$

\begin{tabular}{|c|c|c|c|c|c|c|c|}
\hline Entry & 1 & Catalyst & $\begin{array}{l}\text { Yield } \\
(\%)^{\mathrm{b}}\end{array}$ & $\begin{array}{l}M_{\mathrm{n}}\left(\times 10^{3}\right) \\
\left(M_{\mathrm{w}} / M_{\mathrm{n}}\right)^{\mathrm{d}} \\
\end{array}$ & {$[\alpha]_{\mathrm{D}}{ }^{\mathrm{e}}$} & {$[\phi]_{D}^{e}$} & $\begin{array}{c}\text { Coupling ratio } \\
\mathbf{X}: \mathbf{Y}: \mathbf{Z}^{\mathrm{f}} \\
\end{array}$ \\
\hline $1^{g}$ & 1a $(\mathrm{Me})$ & $\mathrm{CuCl}(\mathrm{OH}) \mathrm{TMEDA}$ & 55 & 2.0 & - & - & 18:79:3 \\
\hline $2^{\mathrm{g}}$ & 1a $(\mathrm{Me})$ & $\mathrm{CuCl}-(S) \mathrm{Phbox}$ & $71(47)^{\mathrm{h}}$ & 4.5 & +20 & +68 & $3: 96: 1$ \\
\hline $3^{\mathrm{g}}$ & $1 \mathbf{a}(\mathrm{Me})$ & $\mathrm{CuCl}-(R) \mathrm{Bnbox}$ & 98 & 3.5 & -75 & -257 & $3: 92: 5$ \\
\hline 4 & $\mathbf{1 b}(\mathrm{Ph})$ & $\mathrm{CuCl}(\mathrm{OH}) \mathrm{TMEDA}$ & 62 & $3.4(1.3)$ & - & - & $11: 71: 18$ \\
\hline 5 & $1 \mathbf{b}(\mathrm{Ph})$ & $\mathrm{CuCl}-(S) \mathrm{Phbox}$ & $91(33)^{\mathrm{h}}$ & $5.0(1.8)$ & -15 & -60 & $3: 95: 2$ \\
\hline 6 & $\mathbf{1 b}(\mathrm{Ph})$ & $\mathrm{CuCl}-(R) \mathrm{Bnbox}$ & 71 & $3.8(1.4)$ & -25 & -101 & $14: 71: 15$ \\
\hline 7 & $\mathbf{1 b}(\mathrm{Ph})$ & $\mathrm{CuCl}-(+) \mathrm{PMP}$ & 0 & - & - & - & - \\
\hline 8 & $1 c(B n)$ & $\mathrm{CuCl}(\mathrm{OH}) \mathrm{TMEDA}$ & $27^{\mathrm{c}}$ & $3.5(1.2)$ & - & - & $7: 87: 6$ \\
\hline 9 & $1 c(B n)$ & $\mathrm{CuCl}-(S) \mathrm{Phbox}$ & $78^{c}$ & $7.7(1.3)$ & +40 & +167 & 0:99:1 \\
\hline 10 & $1 c(B n)$ & $\mathrm{CuCl}-(R) \mathrm{Bnbox}$ & $58^{\mathrm{c}}$ & $5.1(1.3)$ & -56 & -234 & $4: 89: 7$ \\
\hline 11 & 1d $(n \operatorname{Hex})$ & $\mathrm{CuCl}(\mathrm{OH}) \mathrm{TMEDA}$ & 81 & $4.1(1.2)$ & - & - & $12: 87: 1$ \\
\hline 12 & 1d $(n \operatorname{Hex})$ & $\mathrm{CuCl}-(S) \mathrm{Phbox}$ & 95 & $9.1(2.3)$ & +55 & +227 & $0: 97: 3$ \\
\hline 13 & 1d $(n \operatorname{Hex})$ & $\mathrm{CuCl}-(R) \mathrm{Bnbox}$ & 95 & $4.4(1.4)$ & -80 & -323 & 7:90:3 \\
\hline
\end{tabular}

${ }^{\mathrm{a}}[$ Copper $] /[$ ligand $] /[\mathbf{1}]=0.20 / 0.25 / 1,[\mathbf{1}]=0.13 \mathrm{M}$, temp. $=$ r. t., time $=24 \mathrm{~h}, \mathrm{O}_{2}$ atmosphere. ${ }^{\mathrm{b}}$ Methanolethyl acetate-1 $\mathrm{N} \mathrm{HCl}(2 / 1 / 0.3, \mathrm{v} / \mathrm{v})$-insoluble part. ${ }^{\mathrm{c}}$ Methanol-ethyl acetate-1 $\mathrm{N} \mathrm{HCl} \mathrm{(1/3/0.4,} \mathrm{v/v)-insoluble} \mathrm{part.}$ ${ }^{\mathrm{d}}$ Determined by SEC in THF (polystyrene standard). ${ }^{\mathrm{e}} \mathrm{In}$ THF. ${ }^{\mathrm{f}}$ Estimated by ${ }^{1} \mathrm{H}$ NMR analysis. ${ }^{\mathrm{g}}$ Reference 4.

${ }^{\mathrm{h}}$ Methanol-insoluble and THF-soluble part.

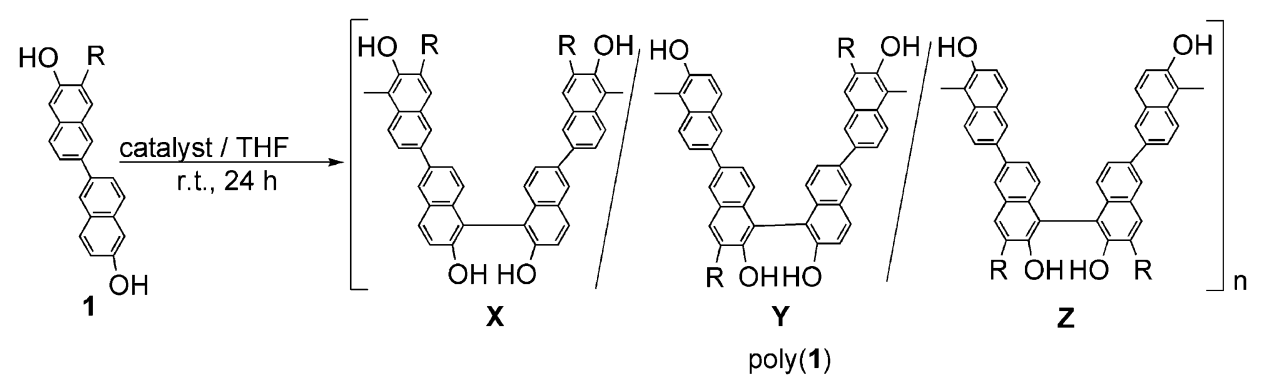

Scheme 2.

$914[\mathrm{M}]^{+}$. Anal. calcd for $\mathrm{C}_{58} \mathrm{H}_{58} \mathrm{O}_{10}: \mathrm{C}, 76.13 ; \mathrm{H}$, 6.39. Found: C, 76.14; H, 6.38.

$\boldsymbol{8 e}:{ }^{1} \mathrm{H}$ NMR $\left(200 \mathrm{MHz}, \mathrm{CDCl}_{3}\right) 10.69(\mathrm{~s}, 1 \mathrm{H},-\mathrm{OH})$, 8.64 (s, $1 \mathrm{H}$, aromatic), $7.82(\mathrm{~d}, 1 \mathrm{H}, J=8.8 \mathrm{~Hz}$, aromatic), 7.56-7.38 (m, 4H, aromatic), 7.17-7.04 (m, $2 \mathrm{H}$, aromatic), $5.31\left(\mathrm{~s}, 2 \mathrm{H},-\mathrm{OCH}_{2} \mathrm{O}-\right), 5.27(\mathrm{~s}, 2 \mathrm{H}$, $\left.-\mathrm{OCH}_{2} \mathrm{O}-\right), 4.89(\mathrm{~s}, 1 \mathrm{H},-\mathrm{OH}), 4.06\left(\mathrm{~s}, 3 \mathrm{H}, \mathrm{CO}_{2} \mathrm{CH}_{3}\right)$, $3.74\left(\mathrm{~s}, 3 \mathrm{H}, \mathrm{CO}_{2} \mathrm{CH}_{3}\right), 3.55\left(\mathrm{~s}, 3 \mathrm{H}, \mathrm{OCH}_{3}\right), 3.52(\mathrm{~s}$, $\left.3 \mathrm{H}, \mathrm{OCH}_{3}\right)$. IR $\left(\mathrm{KBr}, \mathrm{cm}^{-1}\right) 3399,2921,1708,1681$, 1602, 1506, 1440, 1386, 1274, 1151. Mass (FAB): $522 \mathrm{~m} / \mathrm{z}[\mathrm{M}]^{+}$. Anal. Calcd for $\mathrm{C}_{28} \mathrm{H}_{26} \mathrm{O}_{10}: \mathrm{C}, 64.36$; H, 5.02. Found: 64.35; H, 5.05.

\section{Measurements}

${ }^{1} \mathrm{H}$ and ${ }^{13} \mathrm{C}$ NMR spectra were measured on a Varian Unity Inova $\left(500 \mathrm{MHz}\right.$ for $\left.{ }^{1} \mathrm{H}\right)$ or Mercury $200\left(200 \mathrm{MHz}\right.$ for $\left.{ }^{1} \mathrm{H}\right)$ spectrometer. The infrared (IR) spectra were recorded on a Horiba FT-720 spectrometer. The mass (MS) spectra were obtained using a JEOL AX505H. The optical rotation was measured on a Jasco P-1010 polarimeter at $25^{\circ} \mathrm{C}$. The circular dichroism (CD) spectra were obtained with a Jasco
J-720WI apparatus. The high-performance-liquidchromatography (HPLC) analyses were performed on a Jasco 986-PU chromatograph equipped with UV (Jasco 970-UV) and polarimetric (Jasco OR990) detectors at room temperature. The UV-vis absorption (UV) spectra were recorded on a UV2200A (Shimadzu). The fluorescence (FL) spectra were measured using a FluoreMax-2 spectrophotometer. The quantum yield was measured by PL quantum yield analyzer C9920-01 (Hamamatsu Photonics).

\section{RESULTS AND DISCUSSION}

Table I shows the results of the oxidative coupling polymerization (OCP) of $\mathbf{1 b}-\mathbf{d}$ with various copper catalysts (Scheme 2), together with those of the polymerization of 1a (entries 1-3). ${ }^{4 a}$ The polymerization with the TMEDA catalyst afforded a product with a relatively lower number average molecular weight $\left(M_{\mathrm{n}}\right)$ in low to moderate yields $(27-81 \%)$ (entries 4, $8,11)$. The $(+)$ PMP catalyst resulted in no yield (entry 7). The polymerization in the presence of the 


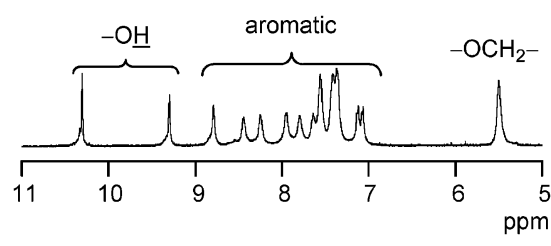

Figure 2. ${ }^{1} \mathrm{H}$ NMR spectrum of poly(1c) obtained with (S)Phbox (Table I, entry 9).

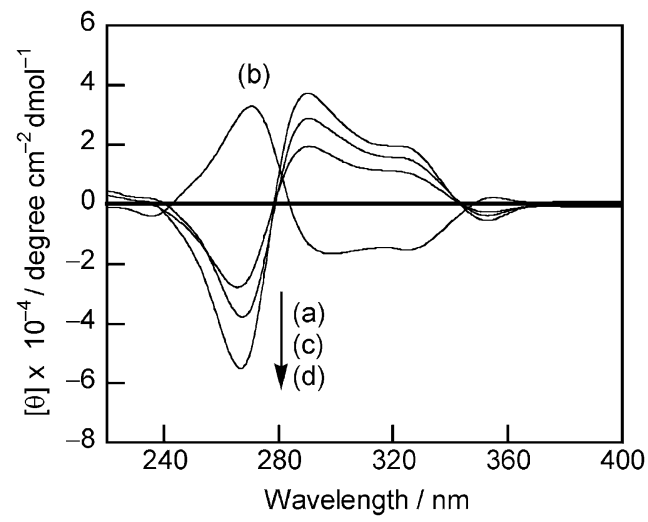

Figure 3. CD spectra of $\operatorname{poly}(\mathbf{1})$ obtained with $(S)$ Phbox: (a) poly(1a) (Table I, entry 2), (b) poly(1b) (Table I, entry 5), (c) $\operatorname{poly}(\mathbf{1 c})$ (Table I, entry 9), and (d) poly(1d) (Table I, entry 12) (monomer unit, in THF).

$\mathrm{CuCl}-(S)$ Phbox catalyst produced a polymer with a good yield and an $M_{\mathrm{n}}$ value of the THF-soluble fraction, $\geq 5.0 \times 10^{3}$ (entries $5,9,12$ ), especially, the polymer obtained by the polymerization of $\mathbf{1 d}$ showed an $M_{\mathrm{n}}$ of $9.1 \times 10^{3}$, which is fully soluble in THF. These results are similar to those observed for the polymerization of $\mathbf{1 a}$.

The ${ }^{1} \mathrm{H}$ NMR spectrum of poly(1c) obtained with $(S)$ Phbox is depicted in Figure 2, and the peaks are assigned as shown in the figure. The CD spectra of the obtained poly(1) using the $\mathrm{CuCl}-(S)$ Phbox catalyst are shown in Figure 3. The spectral patterns of the polymers with positive and negative specific rotations are mirror images of each other and indicates that the latter polymers are rich in the $S$-configuration, ${ }^{5}$ whereas the $R$-structure is preferentially constructed during the polymerization of $\mathbf{1 b}$. The spectral patterns and absorption intensity are in good agreement with those of the observed specific rotation value. The structure of the ester group on the 6,6'-bi-2-naphthol significantly affected the coupling stereochemistry.

The coupling ratio $\mathrm{X}: \mathrm{Y}: \mathrm{Z}$ was calculated from the ${ }^{1} \mathrm{H}$ NMR analysis of the hydroxyl absorption intensities as previously reported. ${ }^{4}$ The ${ }^{1} \mathrm{H}$ NMR spectra of the hydroxyl protons of poly(1b) using the $(S)$ Phbox, $(R)$ Bnbox, and TMEDA catalysts are shown in Figure 4. The internal and terminal hydroxyl protons with different chemical shifts appeared, and
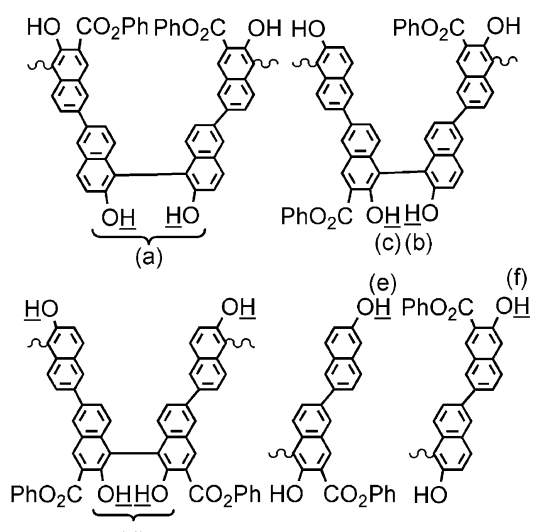

(d)

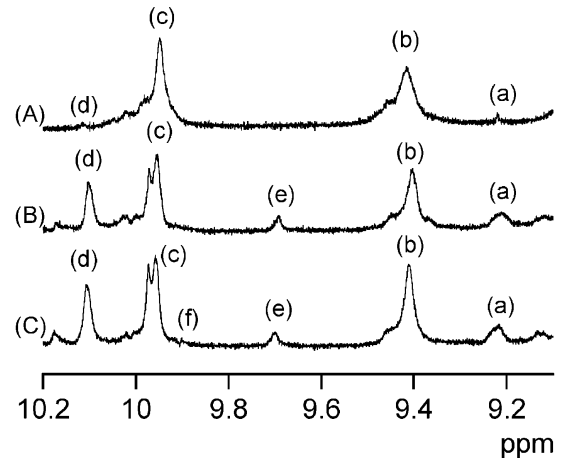

Figure 4. ${ }^{1} \mathrm{H}$ NMR spectra of hydroxyl protons of poly(1) obtained with (A) CuCl-(S)Phbox (Table I, entry 5), (B) CuCl$(R)$ Bnbox (Table I, entry 6), and (C) $\mathrm{CuCl}(\mathrm{OH})$-TMEDA (Table I, entry 4) (in DMSO- $d_{6}, 50^{\circ} \mathrm{C}$ ).

each observed peak was assigned as shown in the figure. The evaluated coupling ratios are shown in Table I. For polymerization with the $(S)$ Phbox catalyst, the cross-coupling reaction predominantly proceeded with the cross-coupling selectivity $\mathrm{Y}$ of $\geq 95 \%$. Especially, the polymer obtained from 1c showed the highest Y-selectivity of 99\%. The structure of the ester groups influenced the coupling-selectivity as well as the coupling enantioselectivity. The cross-coupling selectivity was also observed for the polymerization with the TMEDA and $(R)$ Bnbox catalysts (71-90\%), although they are much lower than those observed for the polymers obtained with the (S)Phbox catalyst.

The coupling stereoselectivity was estimated by the model reaction, that is, the oxidative coupling reaction between 5a-d and 6a-d with $\mathrm{CuCl}-(S) \mathrm{Phbox}$ was conducted (Scheme 3) and the results are listed in Table II (entries 1-4). In every reaction, the corresponding cross-coupling compound $\mathbf{8}$ was produced in good yield (67-89\%) with a high selectivity (>89\%), whose value is quite comparable to that observed for the polymerization. In addition, the cross-coupling compounds 8a-d showed an enantioselectivity of $31(S), 10(R), 28(S)$, and 30\% ee $(S)$, respectively. The CD spectra of the obtained cross-coupling com- 


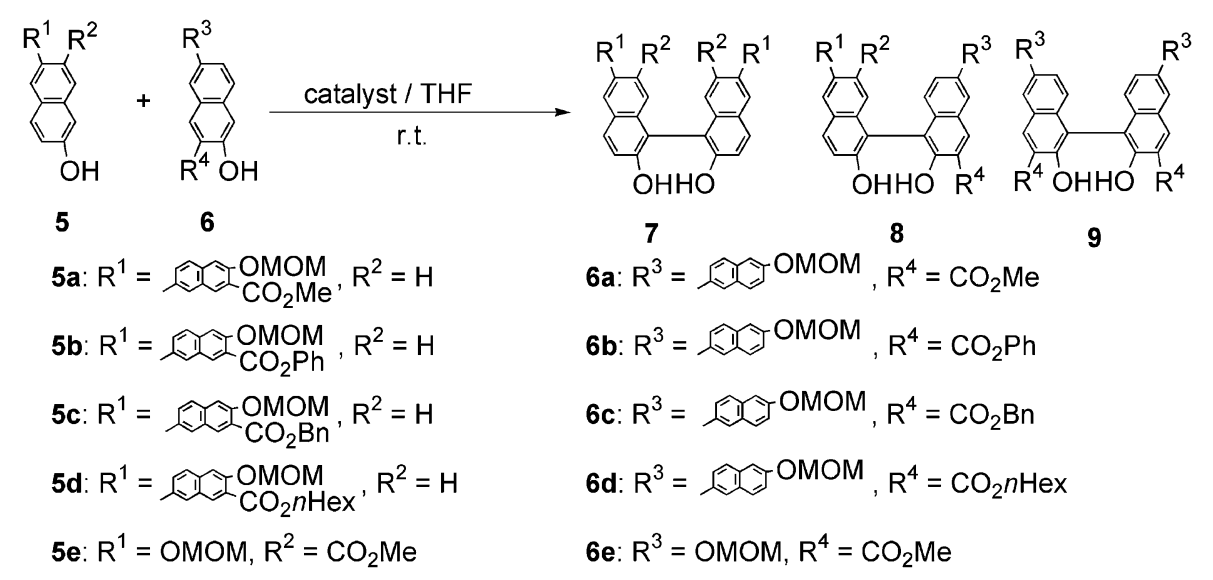

Scheme 3.

Table II. Asymmetric oxidative coupling reaction between 5 and $6^{\mathrm{a}}$

\begin{tabular}{|c|c|c|c|c|c|c|c|c|}
\hline \multirow{2}{*}{ Entry } & \multirow{2}{*}{ Catalyst } & \multirow{2}{*}{5} & \multirow{2}{*}{6} & \multirow{2}{*}{$\begin{array}{l}\text { Time } \\
\text { (h) }\end{array}$} & \multirow{2}{*}{$\begin{array}{c}\text { Coupling ratio } \\
\mathbf{7 : 8 : 9 ^ { \mathrm { b } }}\end{array}$} & \multicolumn{3}{|c|}{ Cross-coupling product 8} \\
\hline & & & & & & 8 & Yield $(\%)^{\mathrm{c}}$ & ee $(\%)^{d}$ \\
\hline $1^{\mathrm{e}}$ & CuCl-(S)Phbox & $5 \mathbf{a}$ & 6a & 5 & $2: 94: 4$ & $8 \mathbf{8 a}$ & 89 & $31(S)$ \\
\hline 2 & $\mathrm{CuCl}-(S) \mathrm{Phbox}$ & $\mathbf{5 b}$ & 6b & 8 & $<1: 89: 10$ & $8 b$ & 88 & $10(R)$ \\
\hline 3 & $\mathrm{CuCl}-(S) \mathrm{Phbox}$ & $5 c$ & $6 c$ & 8 & $<1: 96: 3$ & $8 c$ & 67 & $28(S)$ \\
\hline 4 & CuCl- $(S)$ Phbox & 5d & 6d & 9 & $<1: 95: 4$ & 8d & 82 & $30(S)$ \\
\hline 5 & $\mathrm{CuCl}(\mathrm{OH})-\mathrm{TMEDA}$ & $5 e$ & $6 e$ & 9 & $30: 66: 4$ & $8 e$ & 35 & - \\
\hline 6 & CuCl- $(S)$ Phbox & $5 e$ & $6 e$ & 5 & $8: 80: 12$ & $8 e$ & 72 & $2(R)$ \\
\hline 7 & $\mathrm{CuCl}-(R) \mathrm{Bnbox}$ & $5 e$ & $6 e$ & 9 & $18: 58: 24$ & $8 e$ & 46 & $25(R)$ \\
\hline
\end{tabular}

${ }^{\mathrm{a} C}$ Conditions: $\left[\right.$ copper] $/[$ diamine $] /[\mathbf{5}] /[\mathbf{6}]=0.20 / 0.25 / 1 / 1,[\mathbf{5}+\mathbf{6}]=0.35 \mathrm{M}$, solvent $=\mathrm{THF}, \mathrm{O}_{2}$ atmosphere.

${ }^{\mathrm{b}}$ Ratio of isolated yields. ${ }^{\mathrm{c}}$ Isolated yield. ${ }^{\mathrm{d}}$ Determined by HPLC analysis (Chiralpak AD). ${ }^{\mathrm{e}}$ Reference 4.

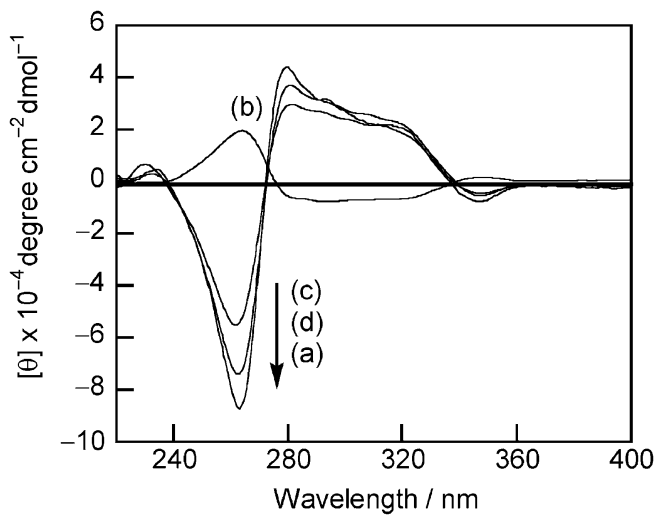

Figure 5. CD spectra of the cross-coupling compounds 8 obtained with (S)Phbox: (a) 8a (Table II, entry 1), (b) $8 \mathbf{b}$ (Table II, entry 2), (c) 8c (Table II, entry 3), and (d) 8d (Table II, entry 4) (binaphthalene unit, in THF).

pounds are demonstrated in Figure 5. The CD curves indicate that the cross-coupling compound having a phenyl ester group is rich in the $R$-configuration, and the others preferentially have the $S$-structure. ${ }^{5}$ The spectral patterns are comparable to those of the corresponding polymers, and these results suggest that the stereochemisty constructed during the polymerization should be controlled in a degree similar to the
Table III. Asymmetric OCP of $\mathbf{2}^{\mathrm{a}}$

\begin{tabular}{|c|c|c|c|c|}
\hline Entry & Catalyst & $\begin{array}{l}\text { Yield } \\
(\%)^{\mathrm{b}}\end{array}$ & $\begin{array}{c}M_{\mathrm{n}}\left(\times 10^{3}\right) \\
\left(M_{\mathrm{w}} / M_{\mathrm{n}}\right)^{\mathrm{c}}\end{array}$ & $\begin{array}{c}{[\alpha]_{\mathrm{D}}} \\
(\mathrm{deg})^{\mathrm{d}}\end{array}$ \\
\hline 1 & $\mathrm{CuCl}(\mathrm{OH}) \mathrm{TMEDA}$ & 30 & $2.8(1.4)$ & - \\
\hline 2 & $\mathrm{CuCl}-(+) \mathrm{PMP}$ & 3 & $1.0(1.7)$ & -14 \\
\hline $3^{\mathrm{e}}$ & $\mathrm{CuCl}_{2}-(-) \mathrm{Sp}$ & 78 & $4.6(1.4)$ & -49 \\
\hline 4 & $\mathrm{CuCl}-(S) \mathrm{Phbox}$ & $99(25)^{\mathrm{f}}$ & $12.7(2.1)$ & 0 \\
\hline 5 & $\mathrm{CuCl}-(R) \mathrm{Bnbox}$ & $92(41)^{\mathrm{f}}$ & $7.2(2.0)$ & 0 \\
\hline
\end{tabular}
temp. $=$ r. t., time $=24 \mathrm{~h}, \mathrm{O}_{2}$ atmosphere. ${ }^{\mathrm{b}}$ Methanol- $1 \mathrm{~N}$ $\mathrm{HCl}(9 / 1, \mathrm{v} / \mathrm{v})$-insoluble part. ${ }^{\mathrm{c}}$ Determined by SEC in THF (polystyrene standard). ${ }^{\mathrm{d}}$ In $\mathrm{THF} .{ }^{\mathrm{e}}\left[\mathrm{CuCl}_{2}\right] /[(-) \mathrm{Sp}] /[2]=$ $0.5 / 1 / 1 .{ }^{\mathrm{f}}$ Methanol-insoluble and THF-soluble part.

model reaction.

The OCP of the unsymmetric naphthalene monomer, 2, with the various copper(I)-diamine catalysts was also carried out (Scheme 4) and the results are listed in Table III. The polymerizations with the TMEDA and (+)PMP catalysts afforded an oligomer as the methanol-1 $\mathrm{N} \mathrm{HCl}(9 / 1, \mathrm{v} / \mathrm{v})$-insoluble fraction in a low yield (entries 1 and 2). In marked contrast, the polymerization with the bisoxazoline catalysts produced a polymer in quantitative yield, whose THFsoluble part showed an $M_{\mathrm{n}}$ of $12.7 \times 10^{3}$ (entry 4). 


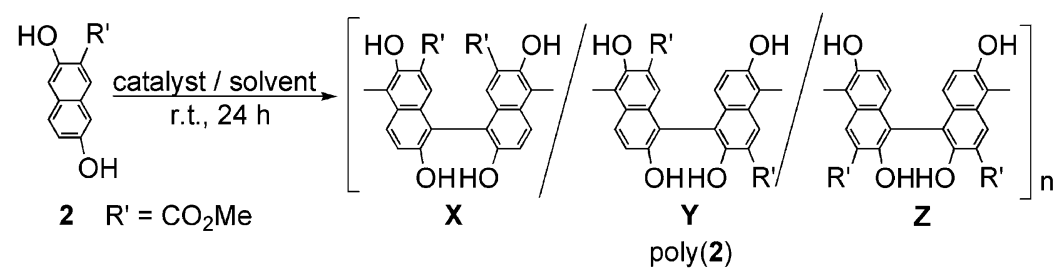

Scheme 4.
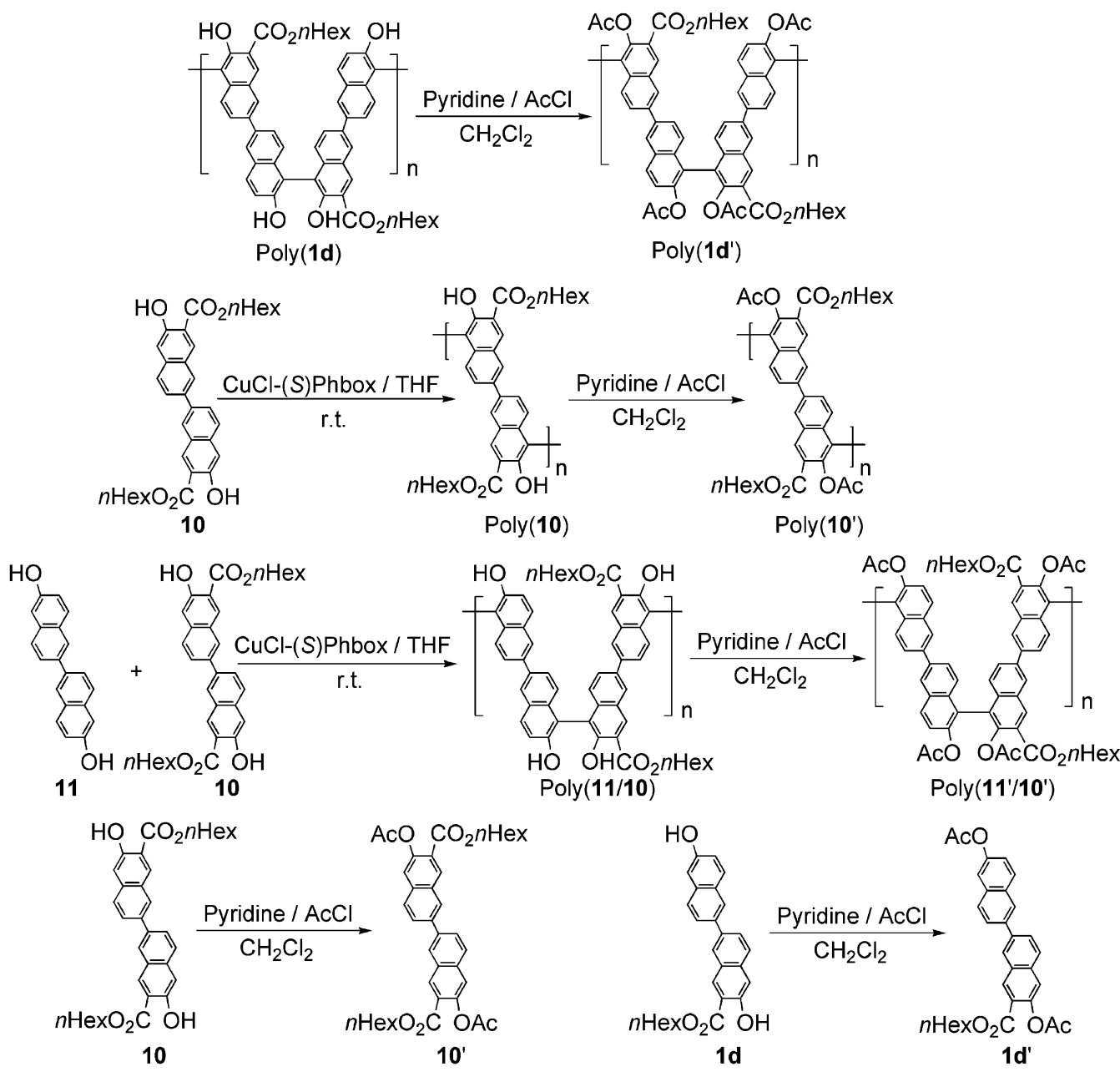

Scheme 5.

The polymerization with the $(-) \mathrm{Sp}$ and $(R)$ Bnbox ligands also resulted in good yields with a much lower $M_{\mathrm{n}}$ value (entries 3 and 5).

The detailed cross-coupling selectivity of the obtained polymers was not clear at present, because some hydroxyl protons with almost the same chemical shift appeared in the ${ }^{1} \mathrm{H}$ NMR analysis. Accordingly, the cross-coupling selectivity, in addition to the stereoselectivity, were estimated from the model reaction between two naphthol derivatives, $5 \mathbf{e}$ and $\mathbf{6 e}$, with various $\mathrm{CuCl}$-diamine catalysts (Scheme 3, Table II, entries 5-7). The reaction with the (S)Phbox catalyst proceeded in the highly cross-coupling selective manner of $80 \%$, whereas the obtained cross-coupl- ing compound 8e showed an enantioselectivity of $2 \%$ ee $(R)$. The reactions with the TMEDA- and (R)Bnbox-catalysts resulted in a much lower yield and cross-coupling selectivity. Therefore, the $\mathrm{CuCl}-$ (S)Phbox catalyst should effectively produce a polymer mainly having a cross-coupling unit during the OCP of 2.

To examine the UV- and FL-properties, the acetylation of the obtained poly(1d) (Table I, entry 12) was performed: $\operatorname{poly}\left(\mathbf{1 d}^{\prime}\right), M_{\mathrm{n}}=14.6 \times 10^{3}, M_{\mathrm{w}} / M_{\mathrm{n}}=$ 4.3. The model compounds, such as poly $\left(\mathbf{1 0}^{\prime}\right)\left(M_{\mathrm{n}}=\right.$ $\left.9.7 \times 10^{3}, M_{\mathrm{w}} / M_{\mathrm{n}}=1.7\right)$, poly $\left(\mathbf{1 1}^{\prime} / \mathbf{1 0}^{\prime}\right)($ cross-coupling selectivity $=93 \%, M_{\mathrm{n}}=10.1 \times 10^{3}, M_{\mathrm{w}} / M_{\mathrm{n}}=$ $1.9),{ }^{4 \mathrm{~b}} \mathbf{1 0}$, and $\mathbf{1 \mathbf { d } ^ { \prime }}$, were also prepared as shown in 


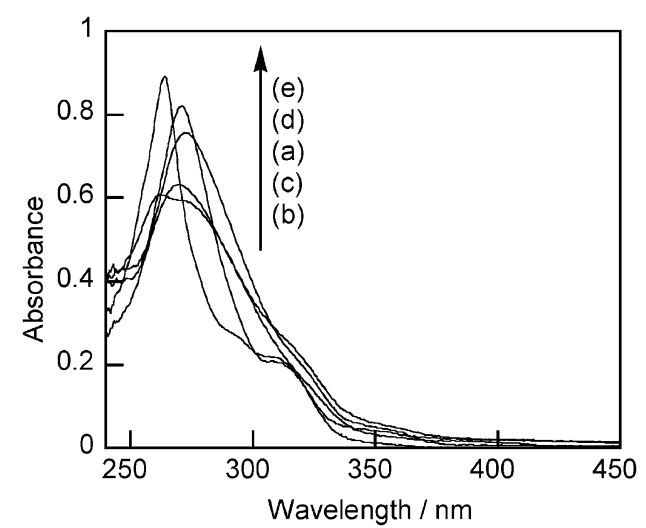

Figure 6. UV-vis absorption spectra of the obtained polymers and the model compounds: (a) poly $\left(\mathbf{1 0}^{\prime}\right)$, (b) poly $\left(\mathbf{1 1}^{\prime} / \mathbf{1 0}^{\prime}\right)$, (c) $\operatorname{poly}\left(\mathbf{1 d ^ { \prime }}\right)$, (d) $\mathbf{1 0}$, and (e) $1 \mathbf{d}^{\prime}\left(C=1.0 \times 10^{-5} \mathrm{M}\right.$, chloroform).

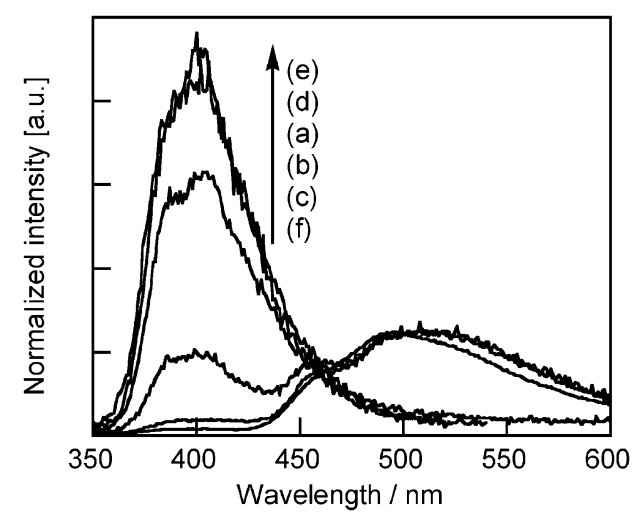

Figure 7. Fluorescence spectra of the obtained polymers and the model compounds (a) poly $\left(\mathbf{1 0}^{\prime}\right)\left(\lambda_{\mathrm{exc}}=304 \mathrm{~nm}\right)$, (b) poly$\left(\mathbf{1 1}^{\prime} / \mathbf{1 0}^{\prime}\right)\left(\lambda_{\mathrm{exc}}=315 \mathrm{~nm}\right)$, (c) poly $\left(\mathbf{1 d}^{\prime}\right)\left(\lambda_{\mathrm{exc}}=313 \mathrm{~nm}\right),(\mathrm{d}) \mathbf{1 0}^{\prime}$ $\left(\lambda_{\mathrm{exc}}=312 \mathrm{~nm}\right)$, and (e) $\mathbf{1 d}^{\prime}\left(\lambda_{\mathrm{exc}}=312 \mathrm{~nm}\right)\left(C=1.0 \times 10^{-5}\right.$ M, chloroform), (f) poly $\left(\mathbf{1 d}^{\prime}\right)\left(\lambda_{\mathrm{exc}}=313 \mathrm{~nm}\right)$ (thin film).

Scheme 5, and these acetylated polymers and model compounds were used for the UV and FL measurements.

The UV absorption spectra in chloroform are shown in Figure 6. The spectral patterns of these compounds were similar to each other with a strong absorption band around $\lambda_{\max }=264-271 \mathrm{~nm}$ and a shoulder around $304-315 \mathrm{~nm}$. Figure 7 (a-e) shows the FL spectra of the polybinaphthols and model compounds in chloroform (concentration: $1.0 \times 10^{-5} \mathrm{M}$ ), measured at an excitation wavelength of around 304$315 \mathrm{~nm}$. The polymer consisting of only the homocoupling unit, poly $\left(\mathbf{1 0}^{\prime}\right)$, showed a spectrum similar to that observed for the model compound $\mathbf{1 0}^{\prime}$. The polymers mainly containing the cross-coupling unit, poly $\left(\mathbf{1 1}^{\prime} / \mathbf{1 0}^{\prime}\right)$ and poly $\left(\mathbf{1 d}^{\prime}\right)$, exhibited red-shifted and broadened emission bands, probably due to the excimer coupling, especially, the FL intensity of the emission around $400 \mathrm{~nm}$ is quite different between these two polymers. The FL spectrum of the poly $\left(\mathbf{1 d}^{\prime}\right)$ film was also measured (Figure 7, f). The similar spectral patterns to that of the dilute solution are observed, although the emission intensity around $400 \mathrm{~nm}$ slightly decreased. These results suggest the intermolecular excimer formation. The polymers, poly $\left(\mathbf{1 0}^{\prime}\right)$ and poly $\left(\mathbf{1 d}^{\prime}\right)$, exhibited a quantum yield of $5 \pm 1 \%$ and $7 \pm 1 \%$, respectively. The coupling structure of the polymer significantly affected the emission properties.

\section{CONCLUSIONS}

The oxidative cross-coupling polymerization of various 6,6'-dihydroxy-2,2'-bianphtalene derivatives with the $\mathrm{CuCl}-(S) \mathrm{Phbox}$ catalyst proceeded in a highly cross-coupling selective manner up to $99 \%$. The polymer containing the cross-coupling unit showed significantly different FL spectra from their model compounds.

Acknowledgment. We thank Dr. J. Kido (Yamagata University) for the PL mesurement. This work was partially supported by Grants-in-Aid for Scientific Researchs (No. 15350066 and 18039003) from the Ministry of Education, Science, Sports, and Culture of Japan.

\section{REFERENCES}

1. a) L. Pu, Chem. Rev., 104, 1687 (2004).

b) L. Ma, P. S. White, and W. Lin, J. Org. Chem., 67, 7577 (2002).

c) A. K-Y. Jen, Y. Liu, Q-S. Hu, and L. Pu, Appl. Phys. Lett., 75, 3745 (1999).

2. a) M. Nakajima, I. Miyoshi, K. Kanayama, S. Hashimoto, M. Noji, and K. Koga, J. Org. Chem., 64, 2264 (1999).

b) J. Gao, J. H. Reibenspies, and A. E. Martell, Angew. Chem., Int. Ed., 42, 6008 (2003).

c) R. Irie, K. Masutani, and T. Katsuki, Synlett, 1433 (2000). d) Z. Luo, Q. Liu, L. Gong, X. Cui, A. Mi, and Y. Jiang, Angew. Chem., Int. Ed., 41, 4532 (2002).

e) H. Somei, Y. Asano, T. Yoshida, S. Takizawa, H. Yamataka, and H. Sasai, Tetrahedron Lett., 45, 1841 (2004).

3. a) T. Temma and S. Habaue, Tetrahedron Lett., 46, 5655 (2005).

b) T. Temma, B. Hatano, and S. Habaue, Tetrahedron, 62, 8559 (2006).

4. a) T. Temma and S. Habaue, J. Polym. Sci., Part A: Polym. Chem., 43, 6287 (2005).

b) T. Temma, B. Hatano, and S. Habaue, Polymer, 47, 1845 (2006).

5. S. R. Wyatt, Q.-S. Hu, X-L. Yan, W. B. Bare, and L. Pu, Macromolecules, 34, 7983 (2001). 